\title{
Biochemical Studies on Carbohydrates.
}

LXX. Application of the Formalin Method (Mas a mu ne and Osaki) to Glycoproteins for Separation of Acid Polysaccharides.

By

Syoh-Iti Osaki and Tokuzo Hasegawa.

（尾崎 正一）（長谷川德 造）

(From the Medico-Chemical Institute, Hokkaido

Imperial University, Sapporo.

Director: Prof. H. Masamune.)

In the preceding work, Masamune and Osaki found that chondroitinsulfuric acid is isolable from cartilage in perfectly pure state if formaldyde is taken advantage of. But the simpleness of the process and the small amount yielded make us raise the question if the product came from chondroitinsulfuric acid in a free state whose existence in cartilage was postulated by C. Th. Mörner. For this reason, we examined the applicability of the process to chondromucoid and in addition to umbilical mucin which involves another acid polysaccharide called mucoitin. Chondroitinsulfuric acid was obtaind from the former glycoprotein in an equally authentic form as from cartilage powder. In the case of the latter more abbreviated operations ${ }^{11}$ could give mucoitin as pure as the one obtained by Suzuki (1938). Calculated from the amount of iodine reduced, the molecular weight of mucoitin approached to 8100 which corresponds to $\mathrm{x}$ of 19 in the provisinal formula below, the structure expressed akin to chondroitin.

$$
\mathrm{C}^{*}-\mathrm{G}-(\mathrm{C}-\mathrm{G}) \mathrm{x}-\mathrm{C}-\mathrm{G}
$$

\footnotetext{
C Acetylchitosamine

G Glucuronic acid

* denotes the component holding free carbonyl
}

1) Mucoitin is, as will be pointed out below, precipitated by phosphotungstic acid. This deproteinizing agent is therefore unavailable, but, in this case, repeated treatment with glacial acetic acid proved satisfactory for removing biuret-giving substances. 
It was seen that mucoitin gives more distinct colour than chondroitinsulfuric acid by Osaki and Turumi's test (unpublished, a procedure of Ehrlich's condensation reaction with dimethylaminobenzaldehyde) after treatment with hot alkali.

\section{Experimental.}

\section{Experiment with chondromucoid.}

Chondromucoid was prepared from trachea cartilage of bull according to C. Th. Mörner (The first method) and isolation of chondroitinsulfuric acid was carried out by following exactly the processes on cartilage powder. $10 \mathrm{gms}$. of the mucoid were taken and the first shaking was conducted with $140 . \mathrm{cc}$. in total of water, $60 \mathrm{cc}$. of $1 \%$ sodium carbonate solution and $3 \mathrm{cc}$. of formalin ( $\mathrm{pH}$ of the mixture, 8.6). Crop, $406 \mathrm{mgms}$. The product behaved toward the reagents of Moli s $\mathrm{ch}$ and biuret tests similarly as the preparations from cartilage powder.

The product analyzed:

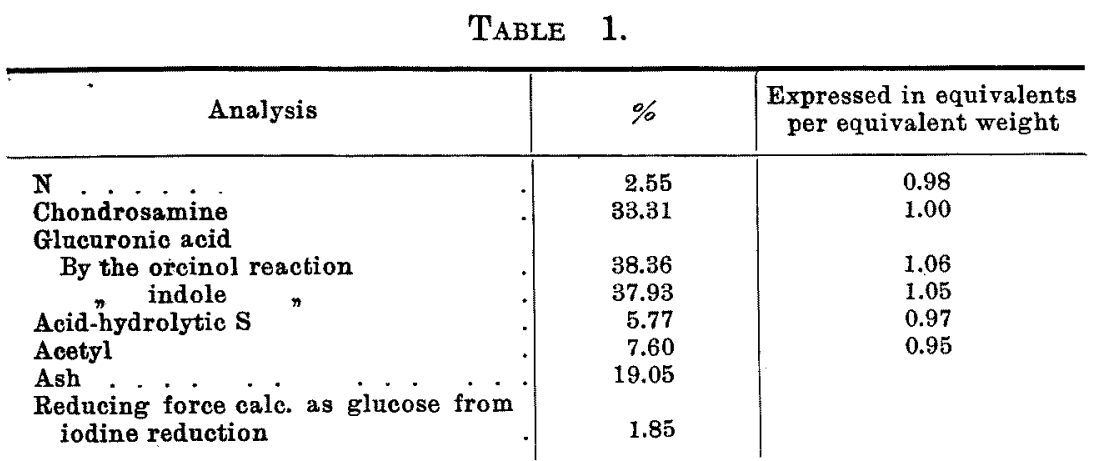

Optical rotation of the product in water :

$$
[\alpha]_{D}^{16}=-0.120 \times 3.013 / 0.0158 \times 1.0019=-22.9^{\circ} \text {. }
$$

II. Experiment with umbilical mucin.

(1) Preparation of mucoitin.

For preparing the mucin the direction of Suzuki (1939) was followed. To isolate mucoitin, attempts led to devise the simple procedure following :-

$5 \mathrm{gms}$. of the mucin were suspended in $100 \mathrm{cc}$. of water and dissolved by means of $50 \mathrm{cc}$. of $1 \% \mathrm{Na}_{2} \mathrm{CO}_{3}$ solution, then to the viscous solution obtained ( $\mathrm{pH} 8.0$ ) were added $10 \mathrm{cc}$. of formalin, more $25 \mathrm{cc}$. of the soda solution in small portions ( $\mathrm{pH}$ was elevated to 8.6) and finally 
water up to $200 \mathrm{cc}$. The mixture was shaken for $24^{\circ}$ hours (room temperature, $13-14^{\circ} \mathrm{C}$.), $\mathrm{pH}$ being adjusted to $8.5^{*}$ from time to time. The final solution was at $\mathrm{pH} 7.6$. It was then acidified to $\mathrm{pH} 4.6$ with a dilute acetic acid, when the maximal precipitation occurred. The deposit separated by centrifuging was treated again with formalin with subsequent acidification and centrifugation in similar manner (liquids taken were $50 \mathrm{cc}$. of water, $65 \mathrm{cc}$. of $1 \% \mathrm{Na}_{2} \mathrm{CO}_{3}$ solution, and $5 \mathrm{cc}$. of formalin; $\mathrm{pH}$ at the outset of shaking, 8.6; duration of shaking, 24 hours ; room temperature, $12-13^{\circ} \mathrm{C}$.). Since the supernatant fluids obtained were turbid, they were subjected together to repeated filtering with suction through paper pulp but could not be changed perfectly transparent. The liquid was next added to with 4 volumes of alcohol and $0.3 \mathrm{gm}$. of sodium acetate and the substance deposited was shaken, after drying in vacuo over $\mathrm{P}_{2} \mathrm{O}_{5}$, in $400 \mathrm{cc}$. of water for 15 hours, but still a turbid solution was given. So for removing the turbidity-causing substance, the use of kaolin was unavoidable, which caused marked loss of the solution. The solution was mixed thoroughly with $40 \mathrm{gms}$. of kaolin, after addition of dilute acetic acid to $\mathrm{pH} 4.4$, and filtered on a Büchner's funnel. The filtrate $(340 \mathrm{cc}$.) was precipitated with 10 volumes of glacial acetic acid (flocculent precipitates) and centrifuged. The centrifugate was washed 3 times with acetic acid ( 1 part of water +10 parts of glacial acetic acid), 8 times with $95 \%$ alcohol ( $\mathrm{pH}$ was elevated to 5.4) and dried, after substituting ether for alcohol, in a desiccator. Yield, $1.35 \mathrm{gms}$. The substance which showed the positive biuret reaction, though faint, was purified twice with kaolin and $90 \%$ acetic acid as follows :-

The first purification. The whole powder was dissolved in $25 \mathrm{cc}$. of water and added to with 15 volumes of glacial acetic acid. The latter produced precipitation immediately on pouring into the solution, but the mixture was shaken as such without separating what had appeared. After 36 hours, the insoluble remainder was centrifuged, washed and dried similar to above. A little sodium acetate was used, when the alcohol washing became turbid due to partial dissolution of the substance.

The second purification. The substance was next taken up in 100 cc. of water and freed from contaminants, which suspended fine in the solution, as follows: the solution was mixed with $10 \mathrm{gms}$. of kaolin, filtered through suction and the kaolin mass was subsequently washed

* With 1\% sodium carbonate solution. 
with three $10 \mathrm{cc}$. portions of water. The filtrate and washings $(105 \mathrm{cc}$. in total) were combined and shaken again with 15 volumes of glacial acetic acid for 24 hours and the insoluble residue was washed and dried as before. For washing with alcohol, a little sodium chloride was used, when necessary, in place of sodium acetate in the preceding case. Crop, 920 mgms. It gave a faintly opalescent solution in water.

(2) Properties of the mucoitin preparation.

Tests. Molisch test developed plain green color. Biuret reaction was not given. Osaki and Turumi's test: $0.4 \mathrm{mgm}$. and more of the preparation showed this reaction $(0.25 \mathrm{mgm}$. was insufficient for the assay), after preliminary heating of its alkaline solution. Phosphotungstic acid precipitated it from the solution in $1 \%$ hydrochloric acid.

Quantitative analysis.

TABle 2.

\begin{tabular}{|c|c|c|}
\hline Analysis & In per cent & $\begin{array}{l}\text { In equivalents per equi- } \\
\text { valent weight }\end{array}$ \\
\hline $\begin{array}{l}\text { N } \\
\text { Glucuronic acid } \\
\text { By indole method } \\
\text { By orcinol method } \\
\text { Glucosamine } \\
\text { Acetyl } \\
\text { Ash : } \\
\text { Reducing force as glucose from } \\
\quad \text { iodino reduction (C a jo ri) }\end{array}$ & $\begin{array}{r}3.21 \\
45.38 \\
46.16 \\
42.63 \\
10.15 \\
0.63 \\
2.38\end{array}$ & $\begin{array}{l}0.93 \\
0.98 \\
0.99 \\
1.00 \\
0.99\end{array}$ \\
\hline
\end{tabular}

Optical rotation in water :

$$
[a]_{D}^{13}=-0.34 \times 3.014 / 0.0158 \times 1.0002=-64.9^{\circ}
$$

Mutarotation was not recognized.

Calculation of the molecular weight.

The molecular weight of mucoitin was calculated as in chondroitinsulfuric acid ${ }^{1)}$ on an ash-free basis from the formula $\left(\mathrm{C}_{14} \mathrm{H}_{21} \mathrm{O}_{11} \mathrm{~N}\right)_{n}$. The iodine use (Cajori method) of acetylglucosamine amounted to 1.06, as expressed as aldehyde equivalent. The number of 21 was given for $n$, as follows :

$917 \mathrm{mgms}$. of the substance reduced $0.242 \mathrm{cc}$. of $0.1 \mathrm{n}$. iodine solution. Therefore,

1) The readers are referred to $M a s$ a $m$ une and 0 saki. 


$$
\begin{aligned}
& 0.0917 \times \frac{100}{100-0.63}: x=\frac{0.242}{1.06}: 20000 \quad(x=g . m .) \\
& \text { m.w. }=8086 .
\end{aligned}
$$

Namely, $n$ in the above formula is approximately $21\left(=\frac{8086}{379}\right)$.

For the same reason as in the case of chondroitinsulfuric acid, 2025 molecules of mucosin appear to constitute one molecule of mucoitin, in other words, the molecules of mucoitin and chondrotin are considered of a similar size.

Parts of the costs of this work were defrayed by a grant from the Foundation for Promotion of Scientific and Industrial Research of Japan and that given by the Government Grant Committee for Scientific Researches of the Education Department.

\section{References.}

Mörner, C. Th. (1889): Skand. Arch. f. Physiol. 1, 210.

M a samune, H. and Osaki, S.-I. (1942): Tohoku Journ. of Exp. Med., 44, 1.

Suzuki, M. (1938): Journ of Biochem. 28, 479.

Suzuki, M. (1939): ibid. 30, 19. 